Studying the Particle Size Effect on Thermal Conductivity for Hybrid Particulate Composite.

Hind.w Abd Allah

\title{
Studying the Particle Size Effect on Thermal Conductivity for Hybrid Particulate Composite.
}

\author{
Hind.W Abd Allah \\ Dep. Of Physics, College of Science, University of Diyala
}

Received 4 April 2016

Accepted 18 May 2016

\section{$\underline{\text { Abstract }}$}

In this research the thermal conductivity of the epoxy resin composites had studied characterized as operating particle size of filler. $\mathrm{SiO}_{2}$ and $\mathrm{MgO}$ are used as filler with three different particle size $(37,75$ and $125 \mu \mathrm{m})$ with volume fraction of $5 \%$. Hybrid composite samples of both filler were prepared using same value of $2.5 \%$ of both in composite. The result shown enhancement in thermal conductivity value of composites compares with the pure and incensement with decreased the grain size of particles additives as a nonlinear relationship. The result given away thermal conductivity of $\mathrm{EP} / \mathrm{MgO}$ composites better than the thermal conductivity $\mathrm{EP} / \mathrm{SiO}$ composite. The hybrid composite samples gives high values of thermal conductivity comparing with $(\mathrm{Ep} / \mathrm{MgO}, \mathrm{EP} / \mathrm{SiO} 2)$ alone for all particle size.

Key word: Thermal conductivity, epoxy, filler, hybrid particulate composites, particle size. 


\title{
Studying the Particle Size Effect on Thermal Conductivity for Hybrid Particulate Composite.
}

Hind.w Abd Allah



\begin{abstract}
الخلاصة
في هذا البحث تمت دراسة التوصيلية الحرارية لمتر اكبات الايبوكسي اعتمادا" على الحجم الحبيبي للحشوات. تم استخدام دقائق اوكسيد المغنسيوم و السيلكا باحجام حبيبة مختلفة بm ( 37,75,125) وبكسر حجمي 5\%. حضرت النماذج الهجينة من كلا النو عين من الدقائق بنسبة 2.5\% لكل نوع الدقائق في المتر اكب .اظهرت النتائج تحسن في قيم التوصيلية الحرارية للمتر اكبات بالمقارنة مع المادة الاساس كما نلاحظ زيادة في قيم التوصيلية مع نقصان الحجم الحبيبي للمو اد المضافة بعلاقة غير خطية . حيث بينت النتائج ان قيم التوصيلية الحرارية للمتر اكب اييوكسي -اوكسيد المغنسيوم افضل من قيم التوصيلية


- اوكسيد المغنسيوم و المنر اكب اييوكسي - سليكا لكافة الاحجام الحبييية. الكلمات المفتاحية : التوصيلية الحر ارية ، الاييوكسي ، الحشوات ، المتر اكبات الدقائقية الهجينة ، الحجم الحبيبي .
\end{abstract}

\section{$\underline{\text { Introduction }}$}

Composites involving particles in a matrix are low cost and widely used. They are used in all plastics, natural and synthetic rubber, and in coating. Fillers used randomly in rubbers then phenolic resin were used recently with wood flour and cellulose to improve physical properties due to aspect ratio. Ideal fillers own physical properties including [1]. Polymers have low thermal conductivity compared with metal and many inorganic materials, to resist transfer of heat by conduction [2]. Materials exhibit obtain of preferred properties, polymers were used as a matrix material mixed with different kinds of fillers (fibers or particles). The thermal conductivity of composite materials which are represented as a multiphase substance depends upon the thermal conductivity of each face, the proportion of each phase, and the distribution of the phase [3]. Epoxy resin was chosen as a matrix due to its good adhesion with the fillers, having improved thermal steadiness resistance to chemical set about and resistance to the degradation [4]. In Particulate-polymer composites the mechanical properties had depended impressively on the particle size, particle-matrix interface adhesion and element loading. Particle size has an understandable effect on these mechanical properties [5]. Silica ( $\mathrm{SiO} 2)$ was 


\section{Studying the Particle Size Effect on Thermal Conductivity for Hybrid Particulate Composite.}

Hind.w Abd Allah

used with thermoplastic polymers to reduce the thermal conductivity and thermal expansion of polymers, mechanism of reinforcing with powders gives a high viscosity and good adhesion, depending on grain size of particles [6] .Materials with a far above the ground thermal conductivity rate must be selected to deal with this difficulty. The thermal conductivity ratio of the inorganic $(\mathrm{MgO})$ is about $42 \mathrm{~W} / \mathrm{m} \cdot \mathrm{K}$, which is around 32 times that of $\mathrm{SiO}_{2}$ [7]. Literature is replete with the use of Particulate Composites material. Zhang et al explored the mechanical and wear properties of $(\mathrm{SiC})$ and alumina $\left(\mathrm{Al}_{2} \mathrm{O}_{3}\right)$ whisker- reinforced epoxy composites. Silicon carbide and alumina whiskers can considerably get better the bending properties and wear resistance of the polymer composites [8]. Calinet al studies effect of kind of particles and ratio reinforced on porosity and thermal conductivity in aluminum $-\mathrm{MgO}$ composites of $5 \%$, $10 \%$ and $15 \%$ RVR produced by melt rousing $\mathrm{MgO}$ particle with particle size of $-105 \mu \mathrm{m}$ were recycled as filler [9]. Zou et.al reported mechanical and dielectric weakness in the EP$\mathrm{SiO} 2$ nanocomposites at different relative humidities and temperatures [10] .

\section{Experimental Work}

\section{Materials used:}

Epoxy resin type (Quick mast 105) was provided by DCP Company / Jordan with specific gravity (1.04) is second-hand with its hardener in ratio (1:3). The epoxy was uniform with a hardener in a container to form a mixture was made use of preparation composites.

The volume fraction of matrix and reinforcement material is calculated from the following equations [11].

$$
\begin{aligned}
\rho_{c} & =\sum V_{i} \cdot \rho_{i}=V_{1} . \rho_{1}+V_{2} \cdot \rho_{2}+\ldots \ldots \ldots \ldots . . .+V_{n} . \rho_{n} \\
V_{p} & =\frac{\rho_{c}}{\rho_{p}} W_{p} \times 100 \% \\
V_{m} & =\frac{\rho_{c}}{\rho_{m}} W_{m} \times 100 \% \\
W_{p} & =\frac{w_{p}}{w_{c}} \times 100 \%
\end{aligned}
$$




\section{Studying the Particle Size Effect on Thermal Conductivity for Hybrid}

Particulate Composite.

Hind.w Abd Allah

$$
\begin{aligned}
& W_{m}=\frac{w_{m}}{w_{c}} \times 100 \% \\
& W_{p}+W_{m}=1 \\
& V_{p}+V_{m}=1
\end{aligned}
$$

Where :

$\mathrm{W}_{\mathrm{m}}, \mathrm{W}_{\mathrm{P}}, \mathrm{W}_{\mathrm{C}}$ : weight matrix, particle, composite respectively .

$\mathrm{V}_{\mathrm{C}}=($ length $*$ width $*$ thickness $)$ of sample

$\mathrm{V}_{\mathrm{m}}, \mathrm{V}_{\mathrm{p}}, \mathrm{V}_{\mathrm{C}}$ : volume fraction of (matrix, particle, composite) respectively

$\rho_{\mathrm{m}}, \rho_{\mathrm{p}}$ : the density of matrix and particle respectively $\left(\mathrm{g} / \mathrm{cm}^{3}\right)$.

Reinforcing Materials:

$\mathrm{SiO}, \mathrm{MgO}$ particles of three different particle sizes $(37,75,125) \mu \mathrm{m}$ were weighted by percent volume $(5 \%)$ and then mixed with epoxy as (epoxy resin- $\mathrm{SiO}_{2}$ ) and (epoxy resin- $\mathrm{MgO}$ ) composites, as well as epoxy polymer reinforced hybrid particles $\left(2.5 \% \mathrm{SiO}_{2}-2.5 \% \mathrm{MgO}\right)$ at the same value.

\section{Sample Preparation}

Hand lay-up molding was used for preparing the samples under test .The epoxies consist of two parts, resin and hardener which need to be uniform in 3:1 volumes to forms the epoxy as matrix . For preparing samples after adding the filler, a weighted amount of $\mathrm{SiO}_{2} / \mathrm{MgO}$ powders were first carefully mixed with a deliberate volume of epoxy. Then a half volume of hardener was added and the result mixture was well mixed so as to obtain a the same composition .The samples for thermal conductivity measurement were made in the form of circular disk with a radius $4 \mathrm{~cm}$.

\section{Thermal conductivity}

The thermal conductivity under steady conditions is the amount of heat flow in unit time through a unit area of body caused by a unit thermal gradient [12]. The heat transfer process 


\section{Studying the Particle Size Effect on Thermal Conductivity for Hybrid Particulate Composite.}

\section{Hind.w Abd Allah}

depends upon structure and state of the thermal substance and temperature difference between any two points. Mainly there are two mechanisms for heat transfer through a solid substance [13]. In solid conductor the free electron and lattice vibration are the dominant mechanism of heat transfer the phonons are the unique mechanism in solid insulator substance [14].

The thermal resistance is reason by assorted kinds of phonon scattering methods: phononphonon scattering, boundary scattering and imperfection or impurity scattering. In order to maximize the thermal conductivity these phonon scattering procedure must be minimized. The scattering of phonons in composite materials is mostly unpaid to the interfacial thermal blockader [15]. The thermal conductivity under steady conditions is the quantity of the heat flow in unit time through a unit area of a body caused by a unit thermal ascent.

$$
\mathrm{J}=-\mathrm{K}(\mathrm{dT} / \mathrm{dx}) \text {. }
$$

where $\mathrm{J}$ : flux of the thermal energy transmitted across a unit area per unit time. $\mathrm{K}$ : is the thermal conductivity coefficient. $\mathrm{dT} / \mathrm{dx}$ : is the temperature gradient.

This equation used only for study state of thermal flow and when the thermal flux does not change with time. The minus sign means that the transfer of heat is starting from hot part to the cold part. [16].

The theoretical thermal conductivity $(\mathrm{K})$ is calculated by the following equation(2):

$$
K=\left(\frac{T_{B}-T_{A}}{d_{s}}\right)=e\left[T_{A}+\frac{2}{r}\left(d_{A}+\frac{1}{4} d_{s}\right) T_{A}+\frac{1}{2 r} d_{s} T_{B}\right]
$$

The heat loss (e) through the unit time (second) and through the area (m2) is calculated by the following formula

$H=I V=\pi r e^{2}\left(T_{A}+T_{c}\right)+2 \pi r e\left\lfloor d_{A} T_{A}+d_{s} \frac{1}{2}\left(T_{A}+T_{B}\right)+d_{B} T_{B}+d_{c} T_{c}\right\rfloor$

$\mathrm{V}=$ Voltage across the terminal of heating (volt)

$\mathrm{I}=$ Electric current pass though heating (Ampere)

$\mathrm{T}_{\mathrm{a}}, \mathrm{T}_{\mathrm{b}}, \mathrm{T}_{\mathrm{c}}$ Temperature across the copper disks $(1,2,3)(\mathrm{k})$

$\mathrm{da}, \mathrm{db}$ and $\mathrm{dc}=$ Thickness of the brass disks $(\mathrm{m})$

$\mathrm{ds}=$ Thickness of the composite specimen $(\mathrm{m})$ 


\section{Studying the Particle Size Effect on Thermal Conductivity for Hybrid \\ Particulate Composite.}

Hind.w Abd Allah

In this work, the Lee's disk technique is used for measuring the thermal conductivity. The geometry of the specimens are $\mathrm{r}=2 \mathrm{~cm}, \mathrm{I}=1.5 \mathrm{amp} ., \mathrm{V}=6 \mathrm{~V}$ When heat source is switched on and the whole is left to equilibrate .

\section{Results and Discussions}

The results of thermal conductivity of $\mathrm{EP} / \mathrm{MgO}$ in different particles size in Table (1) showed that thermal conductivity is decreasing with increasing of $\mathrm{MgO}$ particle size of $\mathrm{EP} / \mathrm{MgO}$.The effect of different reinforcing particles $\left(\mathrm{MgO}, \mathrm{SiO}_{2}\right)$ to epoxy composite is shown at different mixing ratios of particle size on the thermal conductivity. It is clear that the thermal conductivity $\left(\mathrm{W} / \mathrm{m} .{ }^{\circ} \mathrm{C}\right)$ increased with decreasing the particle size ratio from add $\mathrm{MgO}$ filler with improvement results for addition for both reinforced particles system $\left(\mathrm{MgO}, \mathrm{SiO}_{2}\right)$. This is the significant attentiveness at which $\mathrm{MgO}$ particles start making contact with each additional and so the concrete size of the agglomerates happen to large. Accordingly, the heat conduction presentation of epoxy resin composites incorporate $\mathrm{MgO}$ go beyond prospect. With addition of $37 \mu \mathrm{m}$ of $\mathrm{MgO}$, the thermal conductivity of epoxy composite improves by about $226 \%$. In filled polymer composites, fillers are associated and conduction networks are produced in the case of high filler contented. The fillers are remote by the matrix in the container of small filler satisfied [17].

Table (1) thermal conductivity of epoxy and EP/MgO in different particle size

\begin{tabular}{|c|c|c|}
\hline S.NO & Type of specimen & K(W/m.k) \\
\hline 1 & EP & 0.34 \\
\hline 2 & EP/MgO at (125) $\mu \mathrm{m}$ & 4.3 \\
\hline 3 & EP/MgO at (75) $\mu \mathrm{m}$ & 5.6 \\
\hline 4 & EP/MgO at (37) $\mu \mathrm{m}$ & 7.3 \\
\hline
\end{tabular}

Figure (1) shows the thermal conductivity curve of epoxy after addition $\mathrm{MgO}$ in different particle size. Thermal conductivities of all composites increase with filler content, and the trends are similar. The curves can be modeled into three stages .The thermal conductivity increases more rapidly in first stage than in the second and third stages. The turning point from stage 1 to stage 2 appears at large $\mathrm{MgO}$ particle size content for composites with the smallest 


\section{Studying the Particle Size Effect on Thermal Conductivity for Hybrid Particulate Composite.}

Hind.w Abd Allah

particle size. The thermal conductivity of filled polymer systems can be affected to a great extent by surface treatment of the particles. The surface action improves the make contact with between particles and the polymer matrix, decreasing the interfacial thermal resistance. Therefore, the transport of energy during the filler-polymer interface amplifies. In addition the adapted polymer appearance a structure around the particle, which may b different from the structure of the polymer matrix in the bulk [18]. In a few luggages the physico-chemical microand macro-properties of the interfacial level play a more significant function than the properties of the character mechanism [19].

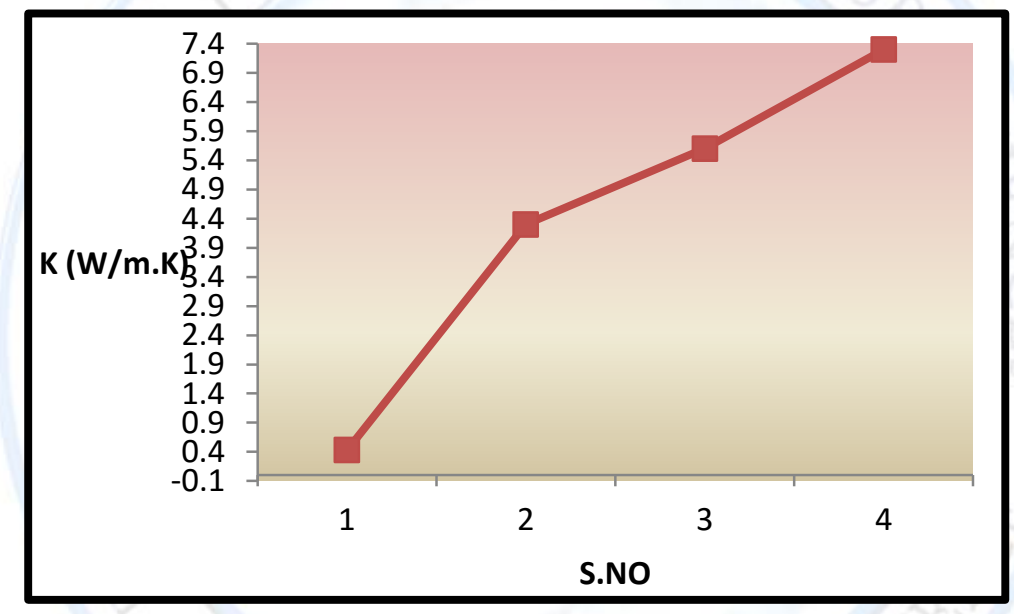

Fig.(1) thermal conductivity of EP/MgO in different particle size.

Figure (2) shows the thermal conductivity curve of epoxy after addition $\mathrm{SiO}_{2}$ in different particles size with $\mathrm{SiO}_{2}$ in different particles size. Thermal conductivity of epoxy/SiO composite decreases with increasing particle size, whereas thermal conductivity results of the epoxy/SiO 2 composites show lower values of thermal conductivity than other $\mathrm{MgO}$ composites - This may be attributed to the increase in polymer free volume, since polymeric chains are pushed apart by the increasing quantity of particles resulting in lower crosslink density and reduced thermal conductivity. In addition, it could also be due to the adsorption of on the surface of $\mathrm{SiO}_{2}$ particle, which may alter the reaction weaken the network of epoxy polymer, thus resulting in lowering of thermal conductivity [11]. 
Studying the Particle Size Effect on Thermal Conductivity for Hybrid

Particulate Composite.

Hind.w Abd Allah

Table (2) thermal conductivity of epoxy and EP/MgO in different particles size .

\begin{tabular}{|c|c|c|}
\hline S.NO & Type of specimen & K(W/m.k) \\
\hline 1 & EP & 0.34 \\
\hline 2 & EP/SiO2 at (125) $\mu \mathrm{m}$ & 2.2 \\
\hline 3 & EP/SiO2 at $(75) \mu \mathrm{m}$ & 4.2 \\
\hline 4 & EP/SiO2 at (37) $\mu \mathrm{m}$ & 6.3 \\
\hline
\end{tabular}

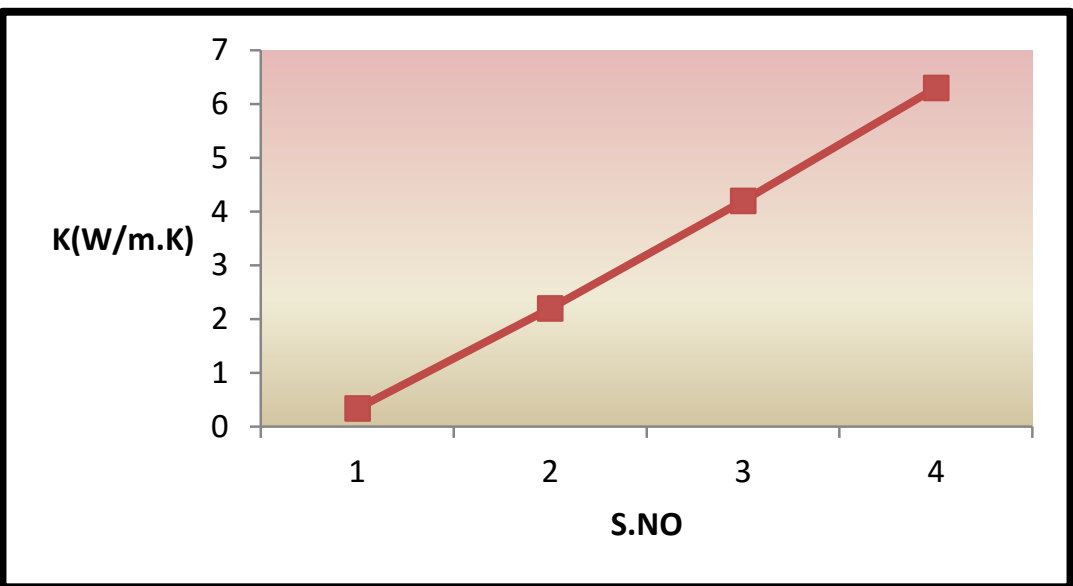

Fig.(2) thermal conductivity of $\mathrm{EP} / \mathrm{SiO}_{2}$ in different particles size .

Table (3) shows the values the thermal conductivity curve of epoxy hybrid particular composite in different particles size. Fig (3) thermal conductivity of epoxy composite increases with decreasing particles size of hybridization particles material. The addition of moreover $\mathrm{SiO} 2$ or $\mathrm{MgO}$ filler to the epoxy reason an likely increase in the soften temperature compared with the untaken matrix (EP). The viscosity of a filled plastic is a purpose of the volume ratio of the filler to the resin. $\mathrm{MgO}$ has a elevated density than $\mathrm{SiO}$, which results in a inferior viscosity. The results show that the percentage of $\mathrm{MgO}$ filler in the composite has a small consequence on softening temperature. This is increase in thermal conductivity contrast with unfilled epoxy that of $\mathrm{SiO} 2$ - filled in composite. The $\mathrm{MgO}$-filled composite as well had a upper thermal diffusivity than $\mathrm{SiO} 2$-filled, connotation thermal transport happen more rapidly in the $\mathrm{MgO}$ filled composite [5]. This is due to the surface area of the record be greater distance particle size interfaces between the record be less when the relay to break the weight and size of the largest particle softer and therefore have influence clear on thermal conductivity. In addition, the 
Studying the Particle Size Effect on Thermal Conductivity for Hybrid

Particulate Composite.

Hind.w Abd Allah

reinforced material has a crystalline structure in which the atoms are arranged in accordance with the three-dimensional crystalline network [20] .

Table (3) thermal conductivity of epoxy and $\mathrm{EP} / \mathrm{SiO}_{2} / \mathrm{MgO}$ (hybrid particular composite) in different particle size.

\begin{tabular}{|c|c|c|}
\hline S.NO & Type of specimen & K(W/m.k) \\
\hline 1 & $\mathrm{EP}$ & 0.34 \\
\hline 2 & $\mathrm{EP} / \mathrm{SiO}_{2} / \mathrm{MgO}$ at $(\mathbf{1 2 5}) \mu \mathrm{m}$ & 5.3 \\
\hline 3 & $\mathrm{EP} / \mathrm{SiO}_{2} / \mathrm{MgO}$ at $(75) \mu \mathrm{m}$ & 7.1 \\
\hline 4 & $\mathrm{EP} / \mathrm{SiO}_{2} / \mathrm{MgO}$ at $(37) \mu \mathrm{m}$ & 8.4 \\
\hline
\end{tabular}

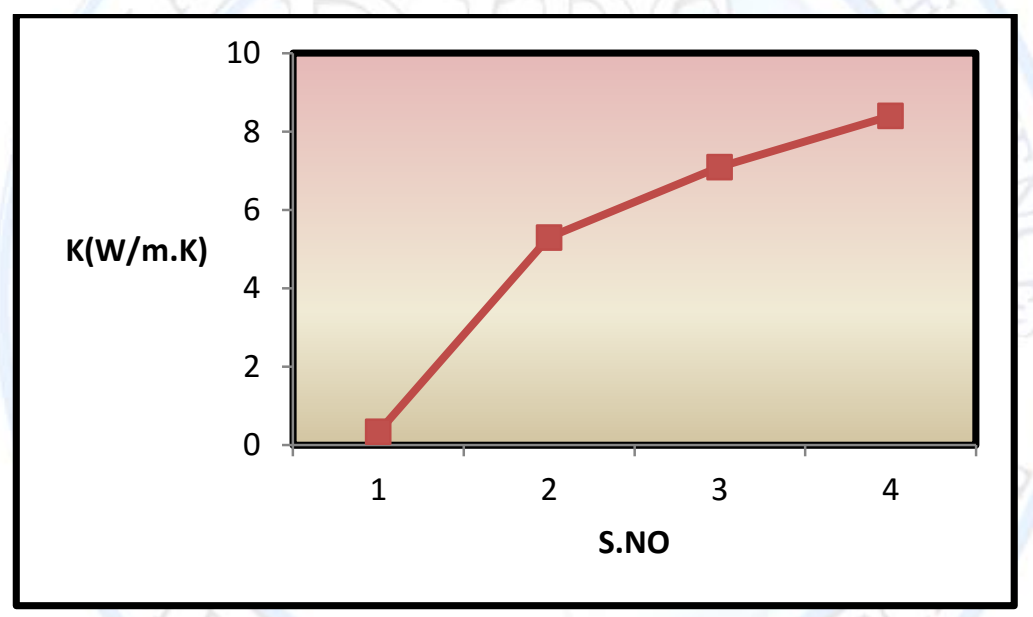

Fig.(3) thermal conductivity of ( $\mathrm{EP} / \mathrm{SiO}_{2} / \mathrm{MgO}$ hybrid particular composite $)$ in different particles size .

Fig.(4) shows the difference of thermal conductivity as a gathering of particle size. The thermal conductivity after hybridization is better than the thermal conductivity without $\mathrm{EP} / \mathrm{MgO}$ composite and $\mathrm{EP} / \mathrm{SiO}_{2}$ composite. For the hybrid filled composites, it is experied that the resulting in high stuffing density of fillers in matrix, and thus heat conductive networks are simply formed in epoxy matrix. In addition, it can also be experied that some $\mathrm{MgO}$ particles are encrusted by epoxy, indicating a strong interfacial adhesion between filler and epoxy. The good quality adhesion of filler and epoxy is one of the important assistance to modify the properties of the composite [6]. Lastly, the experiential nature in this procedure EP/MgO 
Studying the Particle Size Effect on Thermal Conductivity for Hybrid

Particulate Composite.

Hind.w Abd Allah

composite is connected with moderately big bulk voucher. Their additional study is defensible for slighter sized application (e.g., dimensions of hundreds of micrometers such as those second-hand in semiconductor packaging) to see if and how thermal conductivity and moisture absorption individuality are more diverse than what were experiential in this paper.

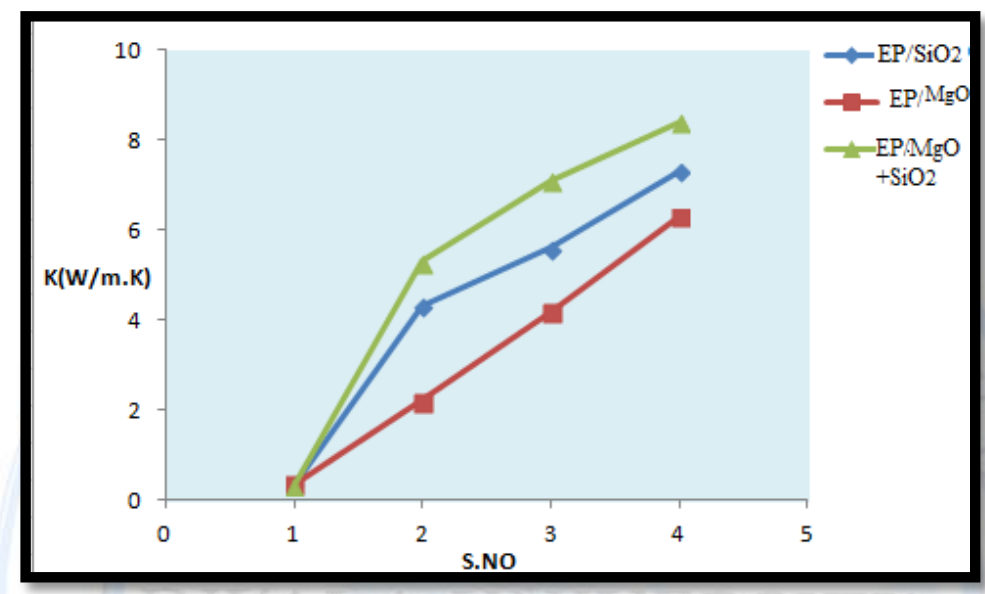

Fig.(4) shows the variation of thermal conductivity $K(\mathrm{~W} / \mathrm{m} . \mathrm{K})$ as a function of particle size of epoxy reinforcement (SiO2/MgO/hybrid particles ).

\section{Conclusion}

Thermal conductivity increase after adding fillers, the used of $\mathrm{MgO}$ particles improved thermal conductivity of epoxy resin better than $\mathrm{SiO}_{2}$ particles due to the high surface to volume ratio of $\mathrm{MgO}$ particle. Thermal conductivity increased with decreasing particles size to both reinforced materials. The thermal conductivity after hybridization is better than the thermal conductivity without epoxy / $\mathrm{MgO}$ composite and epoxy $/ \mathrm{SiO}_{2}$ composite. 
Studying the Particle Size Effect on Thermal Conductivity for Hybrid

Particulate Composite.

Hind.w Abd Allah

\section{References}

1. Bhatnagar M. S, "A Textbook of Polymers [Chemistry and Technology of Polymers], (Processing and Applications)"; Volume II, S. Chand \& Company Ltd; 1st Ed.; 2004.

2. Bushra H. Musa, "Effect of Glass Powder on Some Mechanical Properties of Polymer Matrix Composite Material", Journal of Al-Nahrain University Vol.17 (2), June, (2014), pp.108-115.

3. stanislav rangelov and stergios Pispas; "Polymer Hybrid Nanoparticles From Synthesis to Biomedical Applications ." Taylor \& Francis Group, LLC , (2014).

4. S. Singha and M. J. Thomas: "Permittivity and Tan Delta Characteristics of Epoxy Nanocomposites" Express Polymer Letters, 2(1) (2008) 40-48 .

5. Nakamura Y, Yamaguchi M, Okubo M, Matsumoto," Effects of particle size on mechanical and impact properties of epoxy resin filled with spherical silica." J Appl Polym Sci (1992).

6. Ebewele \& Robert Oboigbaotor; "Polymer Science and Technology"; CRC Press, New York; (2000).

7. In-Bum Jeong, Joung-Sik Kim, Jong-Yong Lee, and Jin-Woong Hong, " Electrical Insulation Properties of Nanocomposites with $\mathrm{SiO} 2$ and $\mathrm{MgO}$ Filler." Transactions on Electrical \& Electronic Materials, Vol. 11, No. 6, pp. 261-265, December 25, (2010).

8. B. Shivamurthy, Siddaramaiah and M.S. Prabhuswamy," Influence of $\mathrm{SiO} 2$ Fillers on Sliding Wear Resistance and Mechanical Properties of Compression Moulded Glass Epoxy Composites." Journal of Minerals \& Materials Characterization \& Engineering, Vol. 8, No.7, (2009).

9. Recep Calin, Muharrem Pul , Zühtü Onur Pehlivanli ," The Effect of Reinforcement Volume Ratio on Porosity and Thermal Conductivity in Al-Mgo Composites." Materials Research, Vol.15,No.6, (2012) .

10. C.Zou , M.Fu, J.C. Fothergill , S.W. Rowe, IEEE conf. On elect. Insulation and dfielectric phenomena, 15-18 Oct.( 2006) , P.321-324 .

11. Deborah. L. Chung "Composite Materials Science and Appliactions" Second Edition Springer-Verlag London Limited, (2010) . 


\section{Studying the Particle Size Effect on Thermal Conductivity for Hybrid \\ Particulate Composite.}

Hind.w Abd Allah

12. Kittel C. "Introduction to Solid State Physics"4th Ed. Wiely Eastern Privat, pp 185$187,(2005)$.

13. Intropera F.P, Dewitt D. P., Bergmah L. and Lavine A. S. "Fundamentals of Heat and Mass Transfer" 6th Ed, John Wiley and Sons, pp 1-5,( 2007).

14. Abdul-Ati M. I., Hemeda O. M., Mosaad M. M. and Hemeda D. M. "Thermal Properties of Pure and Doped (Polyvinyl-Alcohol) PVA" J. Thermal Anal, Vol. 42, 1113-1122, (1994).

15. H. I. Jaafar and A. A.Kareem," Effect of SiC particles and water absorption on thermal conductivity of epoxy reinforcement by (bi-directional) glass fiber." Iraqi Journal of Physics, Vol. 9, No.14,(2011).

16. Francqis Cardarelli, "Materials handbook", Springer-Verlag, London, (2000).

17. M. SAHU , A Study on Thermal Charactertstics of Polymer composites filled with micro sized TiO2 partials ." Master Thesis Department of Mechanical Engineering National Institute of Technology Rourkela , India ,(2014).

18. Shao-Yun Fu, Xi-Qiao Feng, Bernd Lauke, Yiu-Wing Mai ," Effects of particle size, particle/matrix interface adhesion and particle loading on mechanical properties of particulate-polymer composites." Composites: Part B 39. (2008).

19. Khalil Ahmed, Shaikh Sirajuddin Nizami, Nudrat Zahid Raza and Khalid Mahmood," Mechanical, swelling, and thermal aging properties of marble sludge-natural rubber composites." International Journal of Industrial Chemistry, Vol .3, NO.21,(2012).

20. E.A.Ekimov, N.V. Suetin, A.F Popovich," Effect of Microstructure and grain size on the thermal conductivity of high pressure sintered diamond composities", J. Inorganic Materials, Vol.44, No.3 (2008). 